\title{
Do household living arrangements explain gender and ethnicity differences in receipt of support services? Findings from LiLACS NZ Māori and non-Māori advanced age cohorts
}

\author{
Hilary Lapsley ${ }^{1 \star}$, Ngaire Kerse ${ }^{1}$, Simon A. Moyes ${ }^{1}$, Sally Keeling ${ }^{2}$, \\ Marama Leigh Muru-Lanning ${ }^{3}$, Janine Wiles ${ }^{4}$ and Santosh Jatrana ${ }^{5}$ \\ ${ }^{1}$ Department of General Practice and Primary Health Care, University of Auckland, Auckland, New \\ Zealand, ${ }^{2}$ Department of Medicine, University of Otago, Christchurch, New Zealand, ${ }^{3}$ James Henare Māori \\ Research Centre, University of Auckland, Auckland, New Zealand, ${ }^{4}$ Department of Social and Community \\ Health, University of Auckland, Auckland, New Zealand and ${ }^{5}$ Centre for Social Impact, Swinburne \\ University of Technology, Hawthorn, Victoria, Australia \\ ${ }^{\star}$ Corresponding author. Email: h.lapsley@auckland.ac.nz
}

(Accepted 4 October 2018; first published online 19 November 2018)

\begin{abstract}
Services providing practical support are a key component in the spectrum of social care assisting older people to age in place. Te Puāwaitanga o Ngā Tapuwae Kia Ora Tonu/ Life and Living in Advanced Age: A Cohort Study in New Zealand (LiLACS NZ), a longitudinal study of Māori and non-Māori in advanced age, aims to determine predictors of successful ageing and to understand trajectories of health and wellbeing. This paper investigates whether household living arrangements (living alone or with others) might explain previously reported gender and ethnic differences in support service utilisation. We had shown that women and non-Māori received more services than men and Māori despite better health. The results of analyses in this paper show that, as expected, poorer physical function led to increased service use. After controlling for functional status, household living arrangements (living alone) were the next strongest driver of service use. In a fully adjusted model, previously observed differences around gender and ethnicity were no longer significant predictors of support service use. However, gender and ethnicity do shape living arrangements in advanced age. Women in advanced age are more likely to live alone, consequently needing more outside support, whereas men are more likely to have a spouse/partner able to provide care. Māori are more likely to live in multigenerational households, the care available at home meaning they are less likely to qualify for formal support. This study points to a need for understanding how gender and ethnicity interact with living arrangements and suggests that inequities may not be absent when the presence of others in a household renders an older person ineligible for formal care.
\end{abstract}

Keywords: inequalities; advanced ageing; gender; ethnicity; Mãori; support services; social care

(C) Cambridge University Press 2018. This is an Open Access article, distributed under the terms of the Creative Commons Attribution licence (http://creativecommons.org/licenses/by/4.0/), which permits unrestricted re-use, distribution, and reproduction in any medium, provided the original work is properly cited. 


\section{Introduction}

Services providing practical support are a key component in the spectrum of social care resources available to assist older people to live well in terms of health, quality of life and independence (Fine and Keeling, 2010). Health and social care services should be available for those who need them, ideally with the right services provided at the right time in the right place (Ministry of Health, 2002a). Fairness and equity are important values in service provision and social inequalities research is necessary to identify ways in which services may fall short in this respect.

A government report on reducing inequalities in health noted that '[i]n New Zealand, as elsewhere, inequalities in health exist among socioeconomic groups, ethnic groups, people living in different geographic areas, and males and females' (Ministry of Health, 2002b: 3), with 'particular groups ... consistently disadvantaged in regard to health' (2002b: vii). While studies of risk and protective factors dominate the literature on older people's health and health care (Kendig et al., 2014), a body of research internationally examines socio-economic variables, identifying gender and ethnicity inequalities in both distribution and uptake of services (Moriarty and Butt, 2004; Chappell and Penning, 2005). In considering the gender and ethnicity literature it should be kept in mind that research on health and social care is context-specific, reflecting differing policies, service organisation and cultural arrangements within and across different countries (Vlachantoni et al., 2013).

Reporting on gender is ubiquitous in ageing research studies and reporting on ethnicity is common, yet results are seldom interrogated thoroughly (Moriarty and Butt, 2004) and gerontological researchers do not tend to reference scholarly literatures on gender and ethnicity (Gullette, 2011; Torres, 2015). In relation to gender, international literature on ageing has identified inequalities that impact on women, in that older women's health and care needs are often found to be greater than men's, yet they may have less access to care resources; as well, they are more likely than men to have care obligations towards others (Chappell and Penning, 2005).

Ethnicity researchers investigate the ways in which minority ethnic status gives rise to disadvantage in accessing services (Torres, 2015). In such research the term 'ethnic minority' is often used in an all-embracing manner. Racism is a social phenomenon directed towards certain ethnic minorities, yet use of the term 'ethnic minority' may disguise real differences between ethnic groups. Indigeneity and the impacts of colonisation are one such source of difference and this is of relevance to New Zealand where indigenous Māori experience health inequalities (Ministry of Health, 2002b; Harris et al., 2006; Robson and Harris, 2007; Curtis et al., 2010; Hill et al., 2013). The New Zealand government is constitutionally obliged to promote and protect the health of Māori, New Zealand's indigenous population, an obligation stemming from the historic Treaty of Waitangi (Reid et al., 2017).

Inequalities in health do not only arise from stereotyping or discrimination towards particular ethnic groups, or from the material or social positioning, attributes or behaviour of particular ethnic groups. Health inequalities may play out through complex pathways that intertwine macro-social processes, such as ethnicity, with more proximate factors, such as available social support (Berkman et al., 2000). The mediating pathways to inequalities (Ministry of Health, 2002b) have not usually been carefully identified in ageing inequalities research, with 
gender or ethnicity often being presented as the driver of reported differences. Moriarty and Butt (2004: 732) note that in gerontological research 'it has proved to be difficult to specify which factors [relating to inequality] arise from ethnicity and which from other important determinants of health'. Untangling these pathways is a worthwhile research goal.

One proximate factor that may intertwine with gender and ethnicity differences in support service utilisation is household living arrangements, the focus of this study. Living alone may make access to informal care difficult and signal greater need for support services (Kerse et al., 2016b). Gender and ethnicity impact on who lives alone, with women's greater longevity and tendency to marry men older than themselves resulting in women in advanced age being far more likely to live alone than men (Holstein, 2015). Multigenerational households are more likely amongst certain ethnic minority groups in Western countries, meaning that older ethnic minority people are less likely to live alone (Chan and Ermisch, 2015). There are, of course, important differences amongst older people who live alone in their ability to access care. Those who are widowed with children living in the vicinity more readily access informal support than those who are single, childless or living far from other relatives, although within these latter groups there may still be strong social networks, as Allen and Wiles (2014) point out.

One study (Vlachantoni et al., 2013), using data from the English Longitudinal Study of Ageing, examined determinants of receipt of support from a variety of sources, including informal care, and matched support against functional status, as measured by difficulties in activities of daily living (ADLs). Not surprisingly, poorer functional status was by far the strongest determinant of receipt of support generally. The next strongest determinant was marital status (being single). Vlachantoni et al. (2013) claimed that theirs is the first study to weight demographic and socio-economic characteristics as well as health status in relation to amount of support received. However, their study did not examine living arrangements (alone or with others) as a variable. Marital status, which they did include, is a near proxy for living arrangements, although older single people do not necessarily live alone and some married or partnered people may live alone, especially if their spouse/partner is in residential care.

Gender, household living arrangements and provision of care in a Swedish population in advanced age were examined by Larsson and Thorslund (2002). They found that women with dependency needs relied more on relatives and publicly provided support than did men, who relied more on their spouses (the men were less likely to be widowed). Men received more care altogether, after controlling for functional and cognitive impairment. Interestingly, when co-residing (living with others) was controlled for, the gender disparities disappeared. The authors concluded that public care was correctly targeted towards people living alone. However, when informal and public support were added together, it was shown that people living alone (more often women) received less overall support than people living with others and were less likely to be able to remain at home.

It is unclear from the previous research whether gender and ethnicity differences in living arrangements might explain commonly observed gender and ethnic differences in receipt of support. If such patterns of living arrangement do account for such differences, then they might be put down to needs-based targeting (with 
those living alone having greater need for support) rather than demonstrating inequalities in distribution of services.

Te Puāwaitanga o Ngā Tapuwae Kia Ora Tonu/Life and Living in Advanced Age: A Cohort Study in New Zealand (LiLACS NZ) is a New Zealand longitudinal study of two cohorts comprising Māori and non-Māori women and men, aiming to determine predictors of successful advanced ageing and to understand trajectories of health and wellbeing in advanced age (Kerse et al., 2015). It is the first longitudinal study worldwide of an indigenous population in advanced age.

An early finding from LiLACS NZ was that those living alone were more likely to express an unmet need for emotional support than those living with their spouse/ partner or others, although gender and ethnicity were not examined in relation to living arrangements (Kerse and LiLACS NZ, 2015).

Associations between gender, ethnicity and social support were identified in previous research reported from the LiLACS NZ study (Kerse et al., 2016a). They showed that women and non-Māori people of advanced age, despite being more likely to have better health status, were also more likely to receive support services than men and Mãori. However, men and Māori did receive more informal care. Socio-economic deprivation was not significantly related to receipt of support services.

Kerse et al. (2016a) examined functional status and a range of other variables (not including living arrangements) as predictors of receiving support services. Women's functional status was higher than men's, yet women were significantly more likely to receive support services. Lower functional status, expected to predict higher receipt of support services, did so for Māori but not for non-Māori.

Using a fully adjusted model, adjusting for age, functional status, socio-economic deprivation, time in the study, ethnic group and gender, as appropriate, gender differences in receipt of support services remained significant (women were more likely to receive such services) but ethnicity differences did not.

Other data from the same study showed that whilst Māori received significantly more informal care than non-Māori, informal care and formal support services were not substitutes for each other. Participants who received both forms of care were significantly better off, in terms of health-related quality of life.

Building on this previous work, the research presented in this paper introduces living arrangements as a variable. It explores whether already-documented gender and ethnicity differences in support service utilisation amongst Māori and non-Māori women and men in advanced age are explained by differential household living arrangements; and if so, what the implications for understanding inequalities in support service provision would be.

Specifically, the research hypothesis is that living arrangements (living alone as opposed to living with others) will explain previously observed gender and ethnicity differences in receipt of support services. It is also hypothesised that living arrangements are influenced by gender and ethnicity.

\section{Methods/design}

The sampling frame for the LiLACS NZ inception cohorts was the regional boundary of New Zealand's Bay of Plenty and Lakes District Health Board areas 
(excluding the Taupō area), where all Māori aged 80-90 years and non-Māori aged 85 years were identified and invited to participate in a detailed interview and physical assessment (Kerse et al., 2015). Māori hold a very important place in the cultural fabric of New Zealand society. Within a Māori territorial context, the LiLACS NZ study embraces Maori kaumātua (elders) and their whānau (families) from the Bay of Plenty/Te Moana a Toi (the sea of Toi) and the Te Arawa region. Spanning the coast from Tauranga Moana to Te Kaha, and stretching over to Rotorua, the LiLACS NZ research sites include participation and representation from iwi (tribes) and hapū (sub-tribes) including Ngāti Ranginui, Ngāi te Rangi, Te Arawa, Ngāti Awa, Te Whakatōhea, Ngāi Tai, Tūwharetoa ki Kawerau, Tūhoe and Te Whānau à Apanui. In Maori society kaumātua have vital leadership roles in their whānau and are often expected to perform duties within the wider whanau and tribal community. They are respected for their age and accumulation of knowledge and often feature in traditional Māori stories as nurturers of the young and holders of knowledge that is passed on intergenerationally (Durie, 1999). The age selection criterion was different for the two cohorts since Māori life expectancy at birth is seven years lower than for non-Māori and so a broader age range was needed to achieve equivalent numbers in both cohorts.

A total of 937 participants, 421 Māori and 516 non-Māori agreed to participate. Of the 516 non-Māori participants, nearly all were of New Zealand European descent (89\%), 10 per cent identified as other European and 1 per cent were Pacific, Asian or Middle Eastern. Gender and age distribution for Māori matched the general population in their age group; for non-Māori, more men than expected were recruited. Other ways in which the cohorts are representative of the wider New Zealand population are described elsewhere (Dyall et al., 2013; Kerse et al., 2015). Data collection occurred annually until the sixth wave. This research study uses data from the first four waves only (2010-2013 inclusive). At Wave 4 the total number of participants in both cohorts was 438 participants. Death, illhealth or no longer being willing to participate were the main reasons for dropping out of the study and those retained differed from those who dropped out in that they were more likely to have been assessed in earlier waves as functionally independent and were less likely to be depressed (Kerse et al., 2015).

Participants were interviewed using either a full questionnaire or a shorter version, the core questionnaire. Detailed questions around care and support were asked only in the full questionnaire; consequently, only data from participants responding to the full questionnaire are used in the analysis for this paper. In the inception cohort (Wave 1), 671 participants ( $72 \%$ of the total) completed the full questionnaire; of these, 56 per cent were women and 40 per cent Māori. At Wave 4 , the total number of participants in both cohorts numbered 438 participants, with 363 (83\% of the total) completing full questionnaires; 32 per cent of these were Māori and there continued to be 56 per cent women. The average age of Mãori completing the full questionnaire in the inception cohort was 82 and non-Māori 85 years. Those who completed full questionnaires, as compared to core questionnaires, were more functionally able and less likely to be living in residential care. For the purposes of this investigation those living in residential care (only $3.4 \%$ of the total at Wave 1 ) were removed from analysis, since they were 
not eligible for the type of support being examined, that is, support that enables people to continue living independently in home situations.

\section{Instruments/data collection}

Data for the cohort study were collected on a wide range of topics relating to health, function, independence, quality of life, contributions and care, as well as environment, social and cultural matters. Of particular relevance to this paper are data collected on living arrangements (living alone or with others); receipt of support services and informal care; and function, as measured by ADLs via the Nottingham Extended Activities of Daily Living Scale (NEADL) (Essink-Bot et al., 1997). Socio-economic status was measured by the New Zealand Deprivation Index (NZDepIndex) (Salmond et al., 2007).

\section{Definition of support services}

Internationally there are differences in the terminology, types and funding of support provided to older people. The term 'social care' is often used, defined by Lay-Yee et al. (2016) as 'assistance in the activities of daily living'. In the LiLACS NZ study support services are defined as services other than direct health care that are aimed at helping people live independently in their own homes and communities. These include home help for housework, shopping or gardening, and personal care, such as help with dressing, bathing, eating, taking medication or toileting. In New Zealand, these services may be funded in full or in part by the public health or social welfare system, the Accident Compensation Corporation, charities, churches or through (co)-payment by participants. Support services are distinguished from informal care which is defined as receiving unfunded help or assistance with ADLs from whänau/family either in the same household or outside the household. Of course, informal care and formal support services may complement or substitute for each other.

\section{Analysis strategies}

Descriptive statistics for each cohort at baseline (Wave 1), broken down by gender, provide data on age, marital status, household living arrangements and socioeconomic status (Table 1). Data on household living arrangements by ethnic status and gender from Waves 1 and 4 are presented in Figure 1. Receipt or non-receipt of support services is tabulated by functional status (Table 2) and living arrangements (Table 3) across Waves 1-4, broken down by gender and ethnic status and showing confidence intervals. A fully adjusted model is presented in Table 4, relating receiving or not receiving support services to age, gender, social deprivation, living arrangements and functional status. Adjusted and unadjusted odds ratios and confidence intervals are presented. The unadjusted odds ratios are for separate repeated-measures generalised linear models with only the corresponding variable as a predictor. The adjusted odds ratios and $p$-values are for the corresponding variable when included in a singly repeated-measures generalised linear model with all the other variables listed in the table as covariates. 
Table 1. LiLACS NZ cohorts, baseline (Wave 1) socio-demographic data, full questionnaires only, not in residential care

\begin{tabular}{|c|c|c|c|c|}
\hline & $\begin{array}{c}\text { Māori } \\
\text { women }\end{array}$ & $\begin{array}{l}\text { Māori } \\
\text { men }\end{array}$ & $\begin{array}{l}\text { Non-Māori } \\
\text { women }\end{array}$ & $\begin{array}{l}\text { Non-Māori } \\
\text { men }\end{array}$ \\
\hline $\mathrm{N}(\%)$ & $159(60.0)$ & $106(40.0)$ & $201(52.5)$ & $182(47.5)$ \\
\hline \multirow[t]{2}{*}{ Mean age (SD) } & $82.5(2.7)$ & $82.0(2.5)$ & $84.6(0.5)$ & $84.5(0.5)$ \\
\hline & \multicolumn{4}{|c|}{ Frequencies (\%) } \\
\hline \multicolumn{5}{|l|}{ Marital status: } \\
\hline Married/partnered & $33(21.0)$ & $51(50.0)$ & $53(26.6)$ & $120(67.0)$ \\
\hline Widow/widower & $116(73.3)$ & $43(42.2)$ & $129(64.8)$ & $46(25.7)$ \\
\hline Never married/separated/divorced & $9(5.7)$ & $8(7.8)$ & $17(8.5)$ & $13(7.3)$ \\
\hline \multicolumn{5}{|l|}{ Household living arrangements: } \\
\hline Living alone & $81(50.9)$ & $28(26.4)$ & $131(65.2)$ & $60(33.0)$ \\
\hline With spouse only & $30(18.9)$ & $40(37.7)$ & $48(23.9)$ & $106(58.2)$ \\
\hline With spouse and others & $8(5.0)$ & $10(9.4)$ & $5(2.5)$ & $10(5.5)$ \\
\hline With others & $40(25.2)$ & $28(26.4)$ & $17(8.5)$ & $6(3.3)$ \\
\hline \multicolumn{5}{|l|}{ New Zealand Deprivation Index: } \\
\hline 1-4 (least deprived) & $26(16.4)$ & $11(10.4)$ & $50(24.9)$ & $49(26.9)$ \\
\hline $5-7$ & $31(19.5)$ & $31(29.3)$ & $87(43.3)$ & $77(42.3)$ \\
\hline 8-10 (most deprived) & $102(64.2)$ & $64(60.4)$ & $64(31.8)$ & $56(30.8)$ \\
\hline
\end{tabular}

Notes: LiLACS NZ: Te Puāwaitanga o Ngā Tapuwae Kia Ora Tonu/Life and Living in Advanced Age: A Cohort Study in New Zealand. SD: standard deviation.

\section{Results}

\section{Ethnicity, gender, marital status and household living arrangements}

Demographic data on gender, marital status and household living arrangements for LiLACS NZ full questionnaire participants in the inception cohort (Wave 1) are presented in Table 1, categorised by ethnic group and gender (Māori women and men and non-Māori women and men). These data show a higher predominance of women in the Māori cohort than the non-Māori cohort. Māori participants were slightly younger on average (selection criteria allowed for a broader age range for Māori than non-Māori), with an average age of 82 compared to 84 years for non-Maori. Gender disparities in marital status were striking, with a far higher percentage of women than men widowed. This was especially so for Māori women, around three-quarters of whom were widowed. These marital status disparities were echoed in living arrangements. Non-Māori women formed the largest group living alone, followed by Māori women and non-Māori men, and then Māori men, who were least likely to live alone. More men than women lived with their spouse/partner and no others, this being the case for more than half of non-Māori men and nearly 40 per cent of Māori men. A far greater percentage of Māori than non-Māori shared a household with 'spouse/partner and others' or 


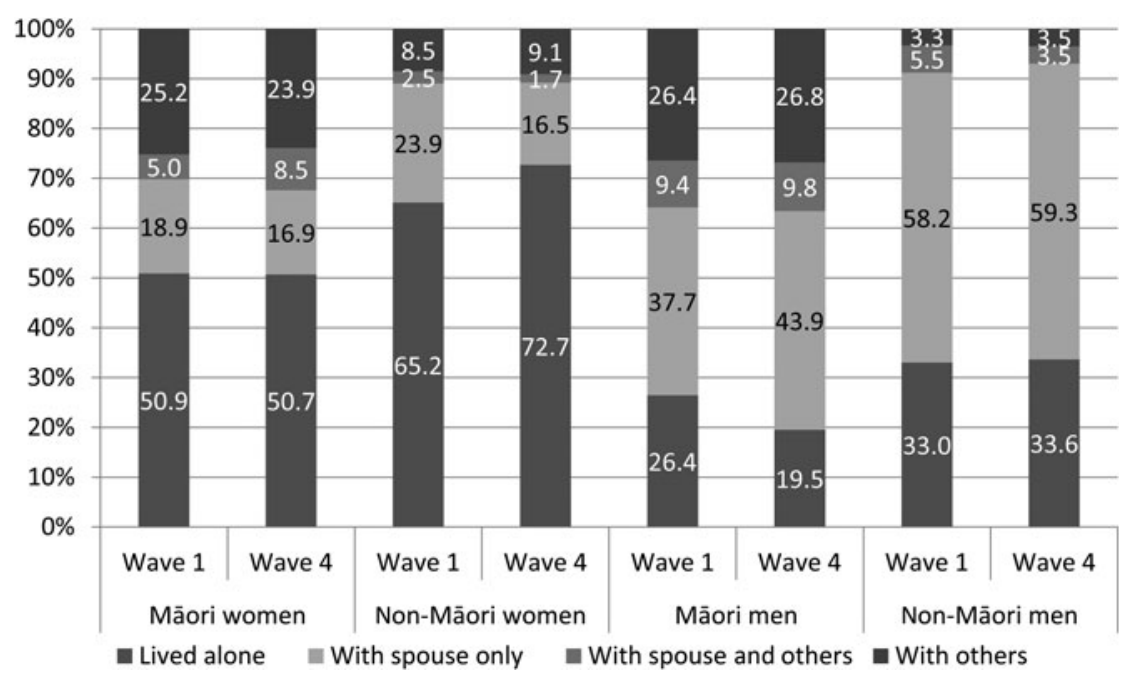

Figure 1. Household living arrangements by ethnicity and gender, Waves 1 and 4 .

'others'. Around two-thirds of Māori lived in lower socio-economic neighbourhoods, as measured by the NZDepIndex, compared to less than one-third of non-Māori.

Figure 1 shows changes in living arrangements over time (data from Waves 1 and 4 of the study). At Wave 1, just over half of Māori women lived alone compared to around two-thirds of non-Māori women; 26 per cent of Māori men and 33 per cent of non-Māori men lived alone. By Wave 4, half of Māori women lived alone (48\%) but the percentage of non-Māori women who lived alone had increased to $73 \%$ per cent. Non-Māori men continued to live alone at around the same rate as in the first wave (34\% versus 33\%), while Māori men were less likely to live alone (19\% compared to $26 \%$ ). Study data show that although more participants were widowed by Wave 4, there was an increase in participants living with non-spousal others (not including those in residential care, since they were excluded from this investigation); there were also fewer participants at Wave 4, some having died and others no longer participating.

\section{Gender, ethnicity and support services}

Table 2 presents data on receipt of support services by ethnic group and gender as well as receipt of support services by functional status (as measured by NEADL), ethnic group and gender over all four cohort waves. It shows that more women than men received support services and more non-Māori than Māori. For women, but not for men, use of support services increased over time in the study. Bringing functional status into the picture, the data show that, as expected, function was generally lower for those who received support services than for those who did not.

\section{Living arrangements and support services}

Research reviewed in the Introduction suggested that living arrangements might account for gender differentials in receipt of support services, and it may well be 
Table 2. Receiving any support service by function, LiLACS NZ participants not in residential care, Waves 1-4

\begin{tabular}{|c|c|c|c|c|c|c|c|c|c|c|c|c|}
\hline & \multicolumn{6}{|c|}{ Women } & \multicolumn{6}{|c|}{ Men } \\
\hline & \multicolumn{3}{|c|}{ Māori } & \multicolumn{3}{|c|}{ Non-Māori } & \multicolumn{3}{|c|}{ Māori } & \multicolumn{3}{|c|}{ Non-Māori } \\
\hline & $\mathrm{N}$ & $\%$ & $95 \% \mathrm{Cl}$ & $\mathrm{N}$ & $\%$ & $95 \% \mathrm{Cl}$ & $\mathrm{N}$ & $\%$ & $95 \% \mathrm{Cl}$ & $\mathrm{N}$ & $\%$ & $95 \% \mathrm{Cl}$ \\
\hline \multicolumn{13}{|c|}{ Do you receive any regular support service?: } \\
\hline Wave 1 & 67 & 43.5 & $35.5-51.7$ & 115 & 57.8 & $50.6-64.7$ & 42 & 42.9 & $32.9-53.3$ & 88 & 48.9 & $41.4-56.4$ \\
\hline Wave 2 & 58 & 45.7 & $36.8-54.7$ & 106 & 60.2 & $52.6-67.5$ & 40 & 44.4 & $34-55.3$ & 76 & 46.6 & $38.8-54.6$ \\
\hline Wave 3 & 37 & 41.1 & $30.8-52.0$ & 92 & 64.8 & $56.3-72.6$ & 20 & 35.7 & $23.4-49.6$ & 60 & 42.9 & $34.5-51.5$ \\
\hline Wave 4 & 36 & 51.4 & $39.2-63.6$ & 76 & 66.7 & $57.2-75.2$ & 15 & 37.5 & $22.7-54.2$ & 54 & 48.6 & $39-58.3$ \\
\hline \multicolumn{13}{|c|}{ Function (mean NEADL score): } \\
\hline \multicolumn{13}{|c|}{ Those not receiving support services: } \\
\hline Wave 1 & 18.8 & & $18.0-19.6$ & 19.2 & & $18.5-19.9$ & 17.4 & & $16.3-18.6$ & 18.9 & & $18.4-19.4$ \\
\hline Wave 2 & 18.6 & & $17.8-19.4$ & 18.7 & & $17.9-19.5$ & 16.9 & & $15.8-18.0$ & 17.2 & & $16.4-17.9$ \\
\hline Wave 3 & 18.9 & & $18.1-19.6$ & 18.8 & & $18.0-19.6$ & 16.0 & & $14.9-17.1$ & 16.8 & & $16.1-17.4$ \\
\hline Wave 4 & 18.3 & & $17.1-19.5$ & 18.9 & & $18.1-19.8$ & 14.5 & & $13.0-16.0$ & 16.8 & & $16.0-17.6$ \\
\hline \multicolumn{13}{|c|}{ Those receiving support services: } \\
\hline Wave 1 & 15.8 & & $14.5-17.1$ & 17.7 & & $17.1-18.2$ & 16.7 & & $15.6-17.8$ & 17.4 & & $16.9-18.0$ \\
\hline Wave 2 & 15.9 & & $14.8-17.0$ & 17.0 & & $16.4-17.7$ & 13.8 & & $12.2-15.4$ & 16.6 & & $15.8-17.4$ \\
\hline Wave 3 & 16.6 & & $15.3-18.0$ & 16.5 & & $15.7-17.3$ & 14.9 & & $12.3-17.5$ & 16.8 & & $15.9-17.6$ \\
\hline Wave 4 & 15.2 & & $13.3-17.1$ & 16.7 & & $15.9-17.5$ & 16.8 & & $15.2-18.4$ & 17.0 & & $16.2-17.8$ \\
\hline
\end{tabular}

Do you receive any regular support service?

Function (mean NEADL score)

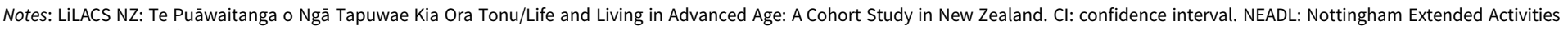
of Daily Living Scale (higher score= better function). 
Table 3. Living arrangements and receipt of support services by gender and ethnic group, LiLACS NZ participants not in residential care, Waves $1-4$

\begin{tabular}{|c|c|c|c|c|c|c|c|c|c|c|c|c|}
\hline & \multicolumn{6}{|c|}{ Women } & \multicolumn{6}{|c|}{ Men } \\
\hline & \multicolumn{3}{|c|}{ Māori } & \multicolumn{3}{|c|}{ Non-Māori } & \multicolumn{3}{|c|}{ Māori } & \multicolumn{3}{|c|}{ Non-Māori } \\
\hline & $\mathrm{N}$ & $\%$ & $95 \% \mathrm{Cl}$ & $\mathrm{N}$ & $\%$ & $95 \% \mathrm{Cl}$ & $\mathrm{N}$ & $\%$ & $95 \% \mathrm{Cl}$ & $\mathrm{N}$ & $\%$ & $95 \% \mathrm{Cl}$ \\
\hline \multicolumn{13}{|c|}{ Do you receive any regular support service?: } \\
\hline Wave 1 & 67 & 43.5 & $35.5-51.7$ & 115 & 57.8 & $50.6-64.7$ & 42 & 42.9 & $32.9-53.3$ & 88 & 48.9 & $41.4-56.4$ \\
\hline Wave 2 & 58 & 45.7 & $36.8-54.7$ & 106 & 60.2 & $52.6-67.5$ & 40 & 44.4 & $34.0-55.3$ & 76 & 46.6 & $38.8-54.6$ \\
\hline Wave 3 & 37 & 41.1 & $30.8-52.0$ & 92 & 64.8 & $56.3-72.6$ & 20 & 35.7 & $23.4-49.6$ & 60 & 42.9 & $34.5-51.5$ \\
\hline Wave 4 & 36 & 51.4 & $39.2-63.6$ & 76 & 66.7 & $57.2-75.2$ & 15 & 37.5 & $22.7-54.2$ & 54 & 48.6 & $39.0-58.3$ \\
\hline \multicolumn{13}{|c|}{ Living alone receiving support services: } \\
\hline Wave 1 & 39 & 49.4 & $37.9-60.9$ & 77 & 59.2 & $50.3-67.8$ & 14 & 53.8 & $33.4-73.4$ & 39 & 66.1 & $52.6-77.9$ \\
\hline Wave 2 & 34 & 50.7 & $38.2-63.2$ & 76 & 61.3 & $52.1-69.9$ & 13 & 59.1 & $36.4-79.3$ & 41 & 69.5 & $56.1-80.8$ \\
\hline Wave 3 & 23 & 50.0 & $34.9-65.1$ & 72 & 67.9 & $58.2-76.7$ & 9 & 75.0 & $42.8-94.5$ & 36 & 75.0 & $60.4-86.4$ \\
\hline Wave 4 & 20 & 57.1 & $39.4-73.7$ & 60 & 72.3 & $61.4-81.6$ & 5 & 71.4 & $29.0-96.3$ & 31 & 83.8 & $68.0-93.8$ \\
\hline \multicolumn{13}{|c|}{ Living with spouse only receiving support services: } \\
\hline Wave 1 & 10 & 34.5 & $17.9-54.3$ & 26 & 54.2 & $39.2-68.6$ & 11 & 28.9 & $15.4-45.9$ & 43 & 40.6 & $31.1-50.5$ \\
\hline Wave 2 & 7 & 29.2 & $12.6-51.1$ & 20 & 62.5 & $43.7-78.9$ & 12 & 31.6 & $17.5-48.7$ & 33 & 34.0 & $24.7-44.3$ \\
\hline Wave 3 & 2 & 13.3 & $1.7-40.5$ & 12 & 52.2 & $30.6-73.2$ & 6 & 24.0 & $9.4-45.1$ & 19 & 23.5 & $14.8-34.2$ \\
\hline Wave 4 & 4 & 33.3 & $9.9-65.1$ & 10 & 52.6 & $28.9-75.6$ & 8 & 44.4 & $21.5-69.2$ & 21 & 31.8 & $20.9-44.4$ \\
\hline
\end{tabular}




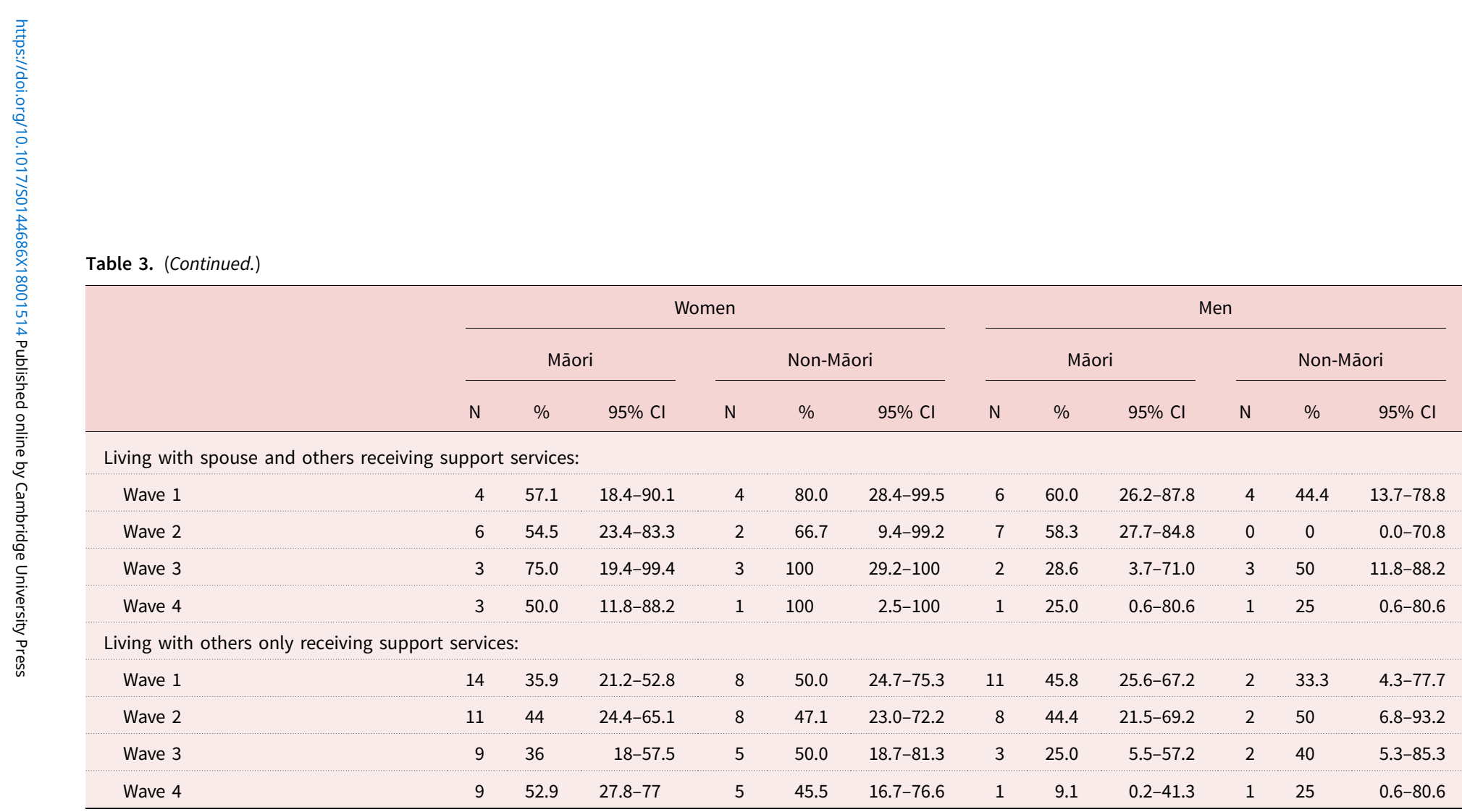


Table 4. Receiving support services for LiLACS NZ participants, Waves 1-4, fully adjusted model: significance table

\begin{tabular}{|c|c|c|c|c|c|c|c|c|}
\hline & $\begin{array}{l}\text { Receiving no } \\
\text { support service }\end{array}$ & $\begin{array}{l}\text { Receiving any } \\
\text { support service }\end{array}$ & $\begin{array}{l}\text { Unadjusted } \\
\text { odds ratio }\end{array}$ & $95 \% \mathrm{Cl}$ & $p$ & $\begin{array}{l}\text { Adjusted } \\
\text { odds ratio }\end{array}$ & $95 \% \mathrm{Cl}$ & $p$ \\
\hline $\mathrm{N}$ & 964 & 982 & & & & & & \\
\hline Mean age (SD) & $84.6(2.4)$ & $85.2(2.1)$ & 1.16 & $1.08-1.23$ & $<0.0001$ & 1.03 & $0.96-1.11$ & 0.4220 \\
\hline $\begin{array}{l}\text { Mean functional status } \\
\text { (11 items) (SD) }\end{array}$ & $9.7(1.5)$ & $9.2(1.6)$ & 0.78 & $0.71-0.86$ & $<0.0001$ & 0.66 & $0.59-0.73$ & $<0.0001$ \\
\hline \multirow[t]{2}{*}{$\begin{array}{l}\text { Mean NZDepIndex } \\
\text { (decile) (SD) }\end{array}$} & $6.9(2.5)$ & $6.6(2.3)$ & 0.93 & $0.87-1.00$ & 0.0372 & 0.96 & $0.90-1.04$ & 0.319 \\
\hline & \multicolumn{2}{|c|}{ Frequencies (\%) } & & & & & & \\
\hline Māori & $406(56.3)$ & $315(43.7)$ & 1 & & & & & \\
\hline Non-Māori & $558(45.6)$ & $667(54.5)$ & 1.83 & $1.30-2.58$ & 0.0005 & 1.53 & $1.03-2.28$ & 0.036 \\
\hline Women & $481(45.0)$ & $587(55.0)$ & 1 & & & & & \\
\hline Men & $483(55.0)$ & $395(45.0)$ & 0.63 & $0.45-0.88$ & 0.0063 & 0.76 & $0.53-1.08$ & 0.129 \\
\hline Lives with others & $615(61.0)$ & $393(39.0)$ & 1 & & & & & \\
\hline Lives alone & $346(37.0)$ & $589(63.0)$ & 2.94 & $2.15-4.02$ & $<0.0001$ & 4.21 & $2.65-6.68$ & $<0.0001$ \\
\hline Married & $450(60.7)$ & $292(39.4)$ & 1 & & & & & \\
\hline Widowed & $433(40.9)$ & $626(59.1)$ & 2.33 & $1.68-3.25$ & $<0.0001$ & 1.07 & $0.67-1.72$ & 0.773 \\
\hline Single not widowed & $78(54.9)$ & $64(45.1)$ & 1.30 & $0.70-2.42$ & 0.4053 & 0.79 & $0.40-1.55$ & 0.486 \\
\hline
\end{tabular}

Notes: LiLACS NZ: Te Puāwaitanga o Ngā Tapuwae Kia Ora Tonu/Life and Living in Advanced Age: A Cohort Study in New Zealand. Cl: confidence interval. SD: standard deviation. NZDepIndex: New

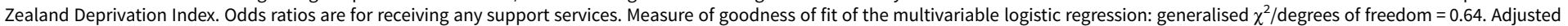
model for receiving support services with age, functional status, ethnicity, gender, living situation and marital status as covariate predictors. 
that the same applies to ethnicity differentials. This section presents findings relating to the main hypothesis of the study, whether living arrangements might explain the gender and ethnicity differences in receipt of support services reported in previous LiLACS NZ publications.

Table 3 presents data on changes in support received over time by living arrangements, gender and ethnic group. For most participants who lived alone, there was an increase in receiving support services from Wave 1 to Wave 4. The increase was from 49 to 57 per cent for Māori women, 59 to 72 per cent for non-Māori women, 54 to 71 per cent for Māori men and 66 to 84 per cent for non-Māori men.

In contrast, for those living with their spouse/partner and no others, support services declined over the four waves of the study, from 34 to 33 per cent for Māori women, 54 to 53 per cent for non-Māori women and 41 to 32 per cent for non-Māori men, the exception being for Māori men living with their spouse/ partner and no others, for whom support services increased from 29 to 44 per cent.

These changes over time showed a widening gap in receipt of support services between men and women, with men who lived alone receiving increasing support. The picture is less clear for those who lived with spouses/partners, but the overall lack of increased support over time suggests that, given declining function in the study members, spouses/partners (more often women) and whanau/families may have shouldered an increasing amount of care. Non-Māori men, by Wave 4 in the study, accounted for around half of the study population living with a spouse/partner alone, and the support they received declined over time.

The other living arrangements, living with spouse/partner and others, or living with others only, were related to intermediate amounts of support service receipt, except for some discrepancies where there were very small numbers in the relevant sub-group.

Table 4 presents a multivariate analysis of receipt of support services, adjusting for age, functional status and socio-economic status (NZDepIndex), as well as ethnic group, gender, living arrangements and marital status. Both unadjusted and adjusted odds ratios are presented, along with confidence intervals and $p$-values. The results suggest that functional status most strongly predicts receipt of support, but that living arrangements (alone or with others) are also a strongly significant predictor. Marital status (married or partnered, widowed or single not widowed) does not function as a proxy for living arrangements, as differences in marital status did not achieve significance at a greater than 0.1 level in relation to receipt of support. Using this adjusted model, it is found that gender and ethnic group predict support less strongly.

\section{Discussion}

These results have shown that living arrangements (living alone or with others) do indeed seem to be a significant pathway through which apparent inequalities in support service receipt in advanced age are mediated. While functional status was the most significant determinant of support service receipt across the whole of the study, household living arrangements were also very significant, more so than gender or ethnic group. So, support services were most likely to be given to 
people needing support who lived alone, gender or ethnicity playing no, or only a small part, in such provision. The implication is that living arrangements in advanced age may often account for the gender and ethnicity differences noted in research on health and social services where data were not adjusted for living arrangements.

However, caution is required in understanding fairness or inequity in service provision for older people, because living arrangements in advanced age are themselves strongly related to gender and ethnicity. More women than men from our study were living alone, and Māori are less likely to live alone than non-Māori. This pattern is socially and culturally shaped. Women have tended to marry men older than themselves and this, combined with their greater longevity, means that they are more likely than men to experience the loss of a spouse or partner and, consequently, often live alone for lengthy periods during advanced age. Māori are more likely than non-Māori to live in multigenerational households, with tradition and economic disparities likely contributors to this difference.

Living arrangements are less frequently explored in ageing research than gender and ethnicity, with some of the few studies examining such interactions cited in our Introduction. This is understandable, since gender and ethnicity are fundamental determinants of social identity and life circumstances. Yet the impact of living arrangements on older people deserves research attention and, as we have argued, caution is warranted in interpreting findings lest they appear to dissolve gender and ethnicity differences and inequities. A framework such as the one provided by Berkman et al. (2000) can help to understand pathways to support for people in advanced age and their care-givers. They describe a cascading process where 'upstream' macro-social processes including inequalities and discrimination impact further 'downstream' on social arrangements such as housing and access to health care, as well as working through psychological mechanisms, such as help-seeking behaviour. Their model pictures the delivery of services in a milieu of social and health factors influencing and interacting with one another. Using this framework, living arrangements in advanced age can be considered as an intermediary pathway towards receipt of support, a pathway that has been shaped by gender and ethnicity.

In assessing the need for state-provided support, living arrangements are usually taken into account; indeed, state provision has often been designed for those who are alone without immediate relatives to care for them (Sundström et al., 2006). Our study suggests that support services were distributed fairly, if living arrangements were part of the criteria for receipt of support. But one should still ask whether distribution of support influenced by living arrangements is free of inequity, since it involves displacing the work of care on to informal carers (Wiles, 2003). Because of the demographics we have noted, this puts more of the burden of care on women and Mãori, since they are more likely to live in the same household as people of advanced age. Further, as mentioned earlier, LiLACS NZ findings reported elsewhere showed that informal care and formal support services are additive, in that using both types of care increases health-related quality of life amongst people in advanced age (Kerse et al., 2016a).

A key finding from a recent micro-simulation exercise intended to provide policy options for the future of New Zealand aged-care services was that reducing residential care would lead to only moderate increases in the utilisation of informal and 
formal care (Lay-Yee et al., 2016). However, social and demographic trends amongst the age groups likely to be giving care to ageing New Zealanders in the coming decades may mean less availability of informal care. We support the conclusion of that study, that increased support for informal care-givers should be a justifiable component in formal support services.

This paper argues that macro-social processes, such as gender and ethnicity, impinge on support service utilisation and need to be considered in attempts to shift the balance of care, lest inequalities be strengthened. In New Zealand, women and Māori already shoulder a higher proportion of informal care for older people, a fact arising both from social and familial arrangements (gender roles, cultural obligations) and mediated via household living arrangements (men and Māori being more likely to live with others). People who live alone receive more formal support, which is understandable. However, older people who live with others may also benefit from formal support in addition to the care available within the household.

\section{Conclusion}

Research on inequities in health and social services for older people can benefit by including living arrangements in the examination of gender and ethnic differentials. Theoretical understandings of social causation, such as the framework for health and social support provided by Berkman et al. (2000), provide a context. Future research could assist more sophisticated rebalancing of care, helping people in advanced age and those who care for them live well, regardless of gender, ethnicity or other potential sources of inequity.

Author ORCIDs. (D) Hilary Lapsley 0000-0003-2116-6491.

Acknowledgements. We thank all LiLACS NZ participants and their whänau for their contributions, Roopu Kaitiaki for their guidance for the study and the local organisations who partnered in the waves of the study, including Western Bay of Plenty Primary Healthcare Organisation, Ngā Matāpuna Oranga Kaupapa Māori PHO, Te Korowai Aroha Trust, Te Rūnanga o Ngati Pikiao, Rotorua Area Health Services, Ngati Awa Rūnanga Archives, Te Rūnanga o Irapuaia, and Te Kaha Medical Centre in conducting the study in the Bay of Plenty and Rotorua. We thank Dr Lorna Dyall and Dr Mere Kepa who were the Māori leadership for LiLACS NZ during Waves 1-4 and the wider LiLACS NZ investigator team.

Author contributions. HL proposed the original idea for the paper and prepared drafts; NK provides leadership to the LiLACS NZ programme, directed statistical analysis for this paper and gave guidance overall; SAM retrieved data, conducted statistical analysis, prepared the figure and tables, and described statistical methods; SK contributed to the design of socio-economic strands of LiLACS NZ data collection and contributed to the literature review for this paper; MLM-L provided oversight for the interpretation of Māori findings in the study. All authors contributed critical input to the whole paper.

Financial support. This work was supported by the Health Research Council of New Zealand (HRC09/ 068B), Ngā Pae o te Māramatanga (the New Zealand National Centre for Research Excellence for Māori) and New Zealand's Ministry of Health. Funders played no role in the research presented in this paper.

Conflict of interest. No potential conflict of interest was reported by the authors.

Ethical standards. Ethics approval for the study was obtained from the Northern X Regional Ethics Committee (NXT 09/09/088) in 2009. The study has been conducted within appropriate ethical guidelines. 


\section{References}

Allen RES and Wiles JL (2014) Receiving support when older: what makes it OK? The Gerontologist 54, 670-682.

Berkman LF, Glass T, Brissette I and Seeman TE (2000) From social integration to health: Durkheim in the new millennium. Social Science and Medicine 51, 843-857.

Chan TW and Ermisch J (2015) Residential proximity of parents and their adult offspring in the United Kingdom, 2009-10. Population Studies 69, 355-372.

Chappell NL and Penning MJ (2005) Family caregivers: increasing demands in the context of 21st century globalization? In Johnson ML (ed.), Cambridge Handbook of Age and Ageing. Cambridge: Cambridge University Press, pp. 455-462.

Curtis E, Harwood M, Riddell T, Robson B, Harris R, Mills C and Reid P (2010) Access and society as determinants of ischaemic heart disease in indigenous populations. Heart, Lung and Circulation 19, 316-324.

Durie M (1999) Kaumatautanga reciprocity: Maori elderly and whanau. New Zealand Journal of Psychology 28, 102-106.

Dyall L, Kepa M, Hayman K, Teh R, Moyes S, Broad JB and Kerse N (2013) Engagement and recruitment of Maori and non-Maori people of advanced age to LiLACS NZ. Australian and New Zealand Journal of Public Health 37, 124-131.

Essink-Bot ML, Krabbe PF, Bonsel GJ and Aaronson NK (1997) An empirical comparison of four generic health status measures. Medical Care 35, 522-537.

Fine M and Keeling S (2010) Social policies for ageing societies: Australasian perspectives. In Dannefer D and Phillipson C (eds), The Sage Handbook of Social Gerontology. London: Sage, pp. 525-539.

Gullette MM (2011) Agewise: Fighting the New Ageism in America. Chicago, IL: University of Chicago Press.

Harris R, Tobias M, Jeffreys M, Waldegrave K, Karlsen S and Nazroo J (2006) Racism and health: the relationship between experience of racial discrimination and health in New Zealand. Social Science and Medicine 63, 1428-1444.

Hill S, Sarfati D, Robson B and Blakely T (2013) Indigenous inequalities in cancer: what role for health care? Australian and New Zealand Journal of Surgery 83, 36-41.

Holstein M (2015) Women in Late Life: Critical Perspectives on Gender and Age. Lanham, MD: Rowman and Littlefield.

Kendig H, Browning CJ, Thomas S and Wells Y (2014) Health, lifestyle, and gender influences on aging well: an Australian longitudinal analysis to guide health promotion. Frontiers in Public Health 2, 2-70.

Kerse N, Lapsley H, Moyes SA, Mules R and Edlin R (2016a) Health, Independence and Caregiving in Advanced Age: Findings from LiLACS NZ. Auckland: School of Population Health, University of Auckland. Available at https://www.fmhs.auckland.ac.nz/en/faculty/lilacs/research/publications.html.

Kerse N and LiLACS NZ (2015) Relationships and Emotional Support: Findings from LiLACS NZ. Auckland: School of Population Health, University of Auckland. Available at https://www.fmhs. auckland.ac.nz/assets/fmhs/faculty/lilacs/research/docs/Relationships\%20and\%20emotional\%20support \%20in\%20advanced\%20age\%20Findings\%20from\%20LiLACS\%20NZ.pdf.

Kerse N, Teh R, Moyes SA, Broad J, Rolleston A, Gott M, Kepa M, Wham C, Hayman K, Jatrana S, Adamson A and Lumley T (2015) Cohort profile: Te Puāwaitanga o Nga Tapuwae Kia Ora Tonu, Life and Living in Advanced Age: a Cohort Study in New Zealand (LiLACS NZ). International Journal of Epidemiology 44, 1823-1832.

Kerse N, Teh R, Moyes SA, Dyall L, Wiles JL, Kepa M, Hayman K, Connolly M, Wilkinson T, Wright St Clair V, Keeling S, Broad J, Jatrana S and Lumley T (2016b) Socioeconomic correlates of quality of life for non-Maori in advanced age: Te Puāwaitanga o Nga Tapuwae Kia Ora Tonu, Life and Living in Advanced Age: a Cohort Study in New Zealand (LiLACS NZ). New Zealand Medical Journal 129, $18-32$.

Larsson K and Thorslund M (2002) Does gender matter? Differences in patterns of informal support and formal services in a Swedish urban elderly population. Research on Aging 24, 308-336.

Lay-Yee R, Pearson J, Davis P, von Randow M, Kerse N and Brown L (2016) Changing the balance of social care for older people: simulating scenarios under demographic ageing in New Zealand. Health \& Social Care in the Community 25, 962-974. 
Ministry of Health (2002a) Health of Older People Strategy 2002. Available at http://www.health.govt.nz/ publication/health-older-people-strategy-2002.

Ministry of Health (2002b) Reducing Inequalities in Health. Wellington: Ministry of Health. Available at http://www.health.govt.nz/publication/reducing-inequalities-health.

Moriarty JO and Butt J (2004) Inequalities in quality of life among older people from different ethnic groups. Ageing \& Society 24, 729-753.

Reid P, Paine S-J, Curtis E, Jones R, Anderson A, Willing E and Harwood M (2017) Achieving health equity in Aotearoa: strengthening responsiveness to Māori in health research. New Zealand Medical Journal 130, 96-103.

Robson B and Harris R (2007) Hauora: Mãori Standards of Health IV: A Study of the Years 2000-2005. Available at http://www.otago.ac.nz/wellington/otago067759.pdf.

Salmond C, Crampton P and Atkinson J (2007) NZDep2006 Index of Deprivation User's Manual. Wellington: Department of Public Health, University of Otago.

Sundström G, Malmberg B and Johansson L (2006) Balancing family and state care: neither, either or both? The case of Sweden. Ageing \& Society 26, 767-782.

Torres S (2015) Expanding the gerontological imagination on ethnicity: conceptual and theoretical perspectives. Ageing \& Society 35, 935-960.

Vlachantoni A, Shaw RJ, Evandrou M and Falkingham J (2013) The determinants of receiving social care in later life in England. Ageing \& Society 35, 321-345.

Wiles JL (2003) Informal caregivers' experiences of formal support in a changing context. Health and Social Care in the Community 11, 189-207.

Cite this article: Lapsley H, Kerse N, Moyes SA, Keeling S, Muru-Lanning ML, Wiles J, Jatrana S (2020). Do household living arrangements explain gender and ethnicity differences in receipt of support services? Findings from LiLACS NZ Māori and non-Māori advanced age cohorts. Ageing \& Society 40, 1004-1020. https://doi.org/10.1017/S0144686X18001514 